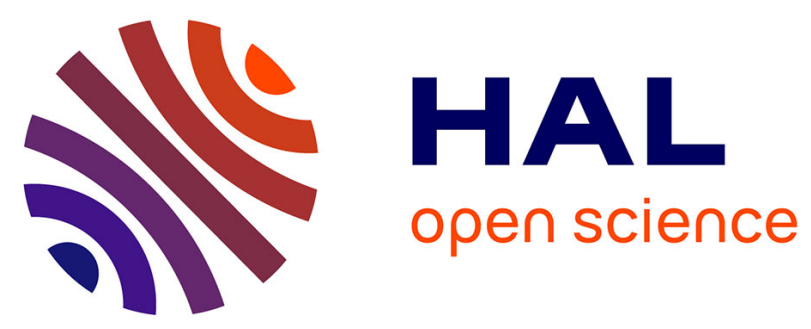

\title{
Mass transfer around a rising bubble in a glass-forming liquid involving oxidation-reduction reaction: Numerical computation of the Sherwood number
}

Franck Pigeonneau, Luiz Pereira, Annabelle Laplace

\section{- To cite this version:}

Franck Pigeonneau, Luiz Pereira, Annabelle Laplace. Mass transfer around a rising bubble in a glass-forming liquid involving oxidation-reduction reaction: Numerical computation of the Sherwood number. Chemical Engineering Science, 2020, pp.116382. 10.1016/j.ces.2020.116382 . hal-03078993

HAL Id: hal-03078993

https://hal-mines-paristech.archives-ouvertes.fr/hal-03078993

Submitted on 17 Dec 2020

HAL is a multi-disciplinary open access archive for the deposit and dissemination of scientific research documents, whether they are published or not. The documents may come from teaching and research institutions in France or abroad, or from public or private research centers.
L'archive ouverte pluridisciplinaire HAL, est destinée au dépôt et à la diffusion de documents scientifiques de niveau recherche, publiés ou non, émanant des établissements d'enseignement et de recherche français ou étrangers, des laboratoires publics ou privés. 


\title{
Mass transfer around a rising bubble in a glass-forming liquid involving oxidation-reduction reaction: Numerical computation of the Sherwood number
}

\author{
Franck Pigeonneau ${ }^{\mathrm{a}, *}$, Luiz Pereira ${ }^{\mathrm{a}, \mathrm{b}}$, Annabelle Laplace ${ }^{\mathrm{b}}$ \\ ${ }^{a}$ MINES ParisTech, PSL Research University, CEMEF, CNRS UMR 7635, CS 10207, Claude \\ Daunesse 06904 Sophia Antipolis cedex, France \\ ${ }^{b} C E A, D E S$, ISEC, DE2D, Univ Montpellier, Marcoule, France
}

\begin{abstract}
The mass transfer of a rising bubble in creeping flow regime is numerically investigated. A reversible oxidation-reduction reaction is taken into account. Two coupled equations are needed to study the oxygen and reduced species transport. Three dimensionless numbers are involved: the Péclet and Damköhler numbers and the ratio of the diffusion coefficient of the reduced species to the diffusion coefficient of oxygen. Numerical computations are applied to a soda-lime-silica and a borosilicate glass-forming liquids. Results are focused on the determination of the Sherwood number. The mass transfer enhances strongly when the chemical reaction is very fast, i.e. at large value of Damköhler number. Correlations to determine the enhancement factor are proposed in the two limits of small and large Péclet numbers. The Sherwood number enhances when the diffusion coefficient of the reduced species increases. A correlation of the Sherwood number is proposed taking into account advection and reaction.
\end{abstract}

Keywords: glass melting; mass transfer; oxidation-reduction reaction; finite element; Sherwood number

\section{Introduction}

The mass transfer between dispersed and continuous phases occurs in many industrial applications (Cussler, 2009, Chap. 8), in nature (Mason et al., 2006) or in food (Liger-Belair, 2005), among others. As it is well known in chemical engineering, the mass transfer between the dispersed and the continuous phases is enhanced by the motion of the discrete phase (Levich, 1962; Clift et al., 1978) with a boundary layer formation. When chemical reactions are involved and according to the "film theory", the mass transfer enhances due to chemical reactions (Sherwood and Pigford, 1952; Danckwerts, 1955; Olander, 1960).

\footnotetext{
*Corresponding author: Tel. +33 (4) 939574 34, Fax +33 (4) 92389752.

Email address: franck.pigeonneau@mines-paristech.fr (Franck Pigeonneau)
} 
In glass melting processes, in which the out-gassing process called "fining process" is the limiting stage, the mass transfer is fundamental to study the overall bubble dynamics in a glass bath (Shelby, 2005). To describe the bubble release at large scale using two-phase Eulerian models (Marchisio and Fox, 2013), the mass transfer coefficient is crucial to know as a function of the bubble motion and chemical reaction rates. The fining process is mainly achieved by adding multivalent elements in raw materials. At high temperature, the multivalent elements are in reduced states, increasing the oxygen solubility (Shelby, 2005). Consequently, the redox state of the glass-forming liquid plays a crucial role during the fining. How oxygen species is transported in glass-forming liquid stays an open question in glass science. Among the main contributors, Schreiber (1986) and Schreiber (1987) compiled redox states for various multivalent elements in synthetic glasses close to natural glass compositions. Schreiber et al. (1986b) studied the redox kinetics for borosilicate glasses. Cicconi et al. (2015) studied the redox equilibrium between two multivalent couples, $\mathrm{Eu}$ and $\mathrm{Fe}$ in magmatic silicate melts. Using in-situ X-ray absorption spectroscopy, they monitored in real-time the behaviour of the two elements as a function of the temperature and oxidation-reduction condition. More recently, Le Losq et al. (2020) performed in-situ XANES spectroscopy in natural silicate (phonolitic melt) to study oxidation and coordination of iron. As already underlined by Cochain et al. (2009), they claimed that the redox transport is strongly correlated to oxygen diffusion.

It is usually assumed that oxidation-reduction reactions in glass-forming liquid are in equilibrium. Nevertheless, due to various species, the chemical equilibrium is not so obvious. Beerkens and de Waal (1990) in the same spirit of works of Crank (1948) took into account the chemical reactions assuming that these reactions are instantaneous. Yoshikawa et al. (1998) followed the same approach in which the moving interface is also introduced. In the last contributions, nothing was achieved to determine the dimensionless mass transfer coefficient, the so-called Sherwood number which will be defined latter. Pigeonneau (2009) studied the mass transfer coefficient for a bubble rising in a glass-forming liquid in which the instantaneous reaction model is derived. Using the boundary layer theory, a simple relation to determine the Sherwood number has been established and applied to study the $\mathrm{O}_{2}$ bubble shrinkage in soda-lime-silicate glasses doped in iron oxide (Pigeonneau et al., 2010) and more recently in borosilicate glass doped in cerium oxide (Pereira et al., 2020). Nevertheless, in (Pigeonneau, 2009), the chemical rate is proportional to the material derivative of the $\mathrm{O}_{2}$ concentration meaning that without motion, the enhancement due to the chemical reaction is vanished.

Beside the chemical reaction contribution, the deformation of gas or liquid inclusion plays an important role on the overall mass transfer. The effect of the bubble shape has been addressed by Figueroa-Espinoza and Legendre (2010) solving the Navier-Stokes equations coupled with advection-diffusion equation for Reynolds numbers larger than one for elliptic bubbles. This work has been extended by taking into account the bubble deformation using an arbitrary Lagrangian-Eulerian method by Jia et al. (2019) or with a Volume of Fluid method by Panda et al. (2020). The mass transfer is also strongly affected by the mobility of the interface between bubble and liquid. Sadhal et al. (1997) provide syntheses of this problem. The rigidity of the interface is mainly due to its contamination. Dani et al. (2006) present a numerical study where the effect of contamination is taken into account on spherical bubble with a partial contamined area at the rear of the bubble. This problem has been particularly studied for bubbles in water by 
Mclaughlin (1996); Liao and McLaughlin (2000b,a); Ponoth and McLaughlin (2000) in which the bubble shape is adapted by satisfying the normal stress balance according a method developped by Ryskin and Leal (1984).

The influence of chemical reaction kinetics on mass transfer around of a spherical gas inclusion has been addressed by Ruckenstein et al. (1971) for first-order irreversible reaction and for small and large Reynolds numbers. Irreversible chemical reactions in unsteady regime have been studied by Soung and Sears (1975). The enhancement of mass transfer due to reaction kinetics has been investigated by Kleinman and Reed (1995) for a quiescent spherical inclusion with a first order irreversible reaction. This work has been extended to a moving drop, bubble or particle in (Kleinman and Reed, 1996). Juncu (2001, 2002b) determined the mass transfer around drop or bubble for first or second order irreversible reactions. Koynov et al. (2005) solved the two-phase flow problem with a front tracking interface method to follow the bubble/liquid interface coupled with mass transfer and two irreversible reactions. Wylock et al. (2008) determined the mass transfer coefficients where four species and two reversible reactions are involved. This contribution has been extended by taking into account the interface contamination and the bubble shape in (Wylock et al., 2011). Bothe et al. (2011) determined the mass transfer for an irreversible chemical reaction of sulfite oxidation using a Volume of Fluid method. The mass transfer coupled with irreversible reactions has been also addressed by Weber et al. (2017); Falcone et al. (2018) for which the bubble interface is tracked by an arbitrary Eulerian-Lagrangian method. Weiner et al. (2019) used the laser-induced fluorescence to experimentally determine the coefficient of mass transfer when a sulfite oxidation reaction is involved. Experimental results are compared to numerical computations using an Arbitrary Eulerian-Lagrangian to track interface.

In framework of glass science, Subramanian and Chi (1980) studied the mass transfer around a single bubble at rest in a molten glass taking into account the chemical kinetics of a first-order irreversible reaction. Pigeonneau et al. (2014) studied the case of reversible reaction between two species in the case of rising bubble in Stokes regimes. Based on approximate solutions, simple expressions of the Sherwood number are also established. Even when the bubble does not move, the enhancement due to chemical reaction is established. Nevertheless, chemical reactions studied in the previous contributions are limited to simple reaction like $A \longrightarrow B$ or $A \rightleftharpoons B$ meaning that the chemical reaction rate remains linear. However, the oxidation-reduction reactions in glass are usually non-linear. Consequently, the purpose of this work is to determine the Sherwood number for the coupled problem of advection-diffusion-reaction with non-linear oxidation-reduction reaction. The effect of the diffusion of the multivalent element is carefully addressed. The purpose is to find expressions to easily evaluate the Sherwood number.

In the following, section 2 describes the problem statement of advection-diffusionreaction equations. The numerical method to solve the system of equations is detailed in $\S 3$. Results and discussion are the purpose of section 4. Finally, conclusions are drawn in the last section of the article. 


\section{Problem statement}

\subsection{General formulation}

A spherical bubble of radius $a$ is rising in a glass-forming liquid at rest. The bubble size is assumed constant even in the presence of mass transfer. Due to the time scale separation, the assumption of constant radius is justified, see (Pigeonneau et al., 2010) for more details. Experimentally, the growth or shrinkage rate is three orders of magnitude lower that the rising velocity of the bubble (Pigeonneau et al., 2010; Pereira et al., 2020). The Reynolds number is assumed to be small, corresponding to small bubbles rising in a viscous liquid. According to Clift et al. (1978), the conditions to have spherical bubble and creeping flow are fulfilled. Moreover as it has been shown in (Jucha et al., 1982; Hornyak and Weinberg, 1984; Li and Schneider, 1993), the bubble/glass-forming liquid interface is considered completely mobile (shear free boundary condition). Consequently, the general solution established by Hadamard (1911) and Rybczynski (1911) is used to describe the flow motion around the bubble. The balance between the drag and the buoyancy force gives the terminal rising velocity:

$$
V_{\mathrm{HR}}=\frac{g a^{2}}{3 \nu},
$$

where $g$ is the gravity acceleration, $\nu=\mu / \rho$ is the kinematic viscosity of the liquid and $\rho$ the liquid density.

Let an oxidation-reduction reaction between oxidised species $\mathrm{M}^{(\mathrm{n}+\mathrm{k})+}$ and reduced species $\mathrm{M}^{\mathrm{n}+}$ given by (Schreiber et al., 1986a)

$$
\mathrm{M}^{(\mathrm{n}+\mathrm{k})+}+\frac{k}{2} \mathrm{O}^{2-} \rightleftharpoons \mathrm{M}^{\mathrm{n}+}+\frac{k}{4} \mathrm{O}_{2} .
$$

It is usually admitted that the activity of the anion $\mathrm{O}^{2-}$ in glass-forming liquid is one. This activity is linked to the basicity of the liquid depending on the composition (Duffy and Ingram, 1976; Bach et al., 2001). The equilibrium constant is then written as follows

$$
K_{\mathrm{M}^{(\mathrm{n}+\mathrm{k})+/ \mathrm{n}+}}=\frac{C_{\mathrm{M}^{\mathrm{n}+}} C_{\mathrm{O}_{2}}^{k / 4}}{C_{\mathrm{M}^{(\mathrm{n}+\mathrm{k})+}}},
$$

in which $C_{\mathrm{M}^{\mathrm{n}+}}$ and $C_{\mathrm{M}^{(\mathrm{n}+\mathrm{k})}+}$ are respectively the molar concentrations of reduced and oxidised species of $\mathrm{M}$ and $C_{\mathrm{O}_{2}}$ the molar concentration of dissolved oxygen. Remark that the oxygen solubility, defined below, is taken into account in the equilibrium constant as explained in (Beerkens and de Waal, 1990; Pigeonneau, 2009).

At the bubble/liquid interface, the chemical potentials in the two phases are commonly used. This equilibrium is a function of the partial pressure of oxygen inside the bubble $P_{\mathrm{O}_{2}}$ and the molar concentration in the liquid given by the Henry's law:

$$
C_{\mathrm{O}_{2}, 0}=L_{\mathrm{O}_{2}} P_{\mathrm{O}_{2}}
$$

in which $L_{\mathrm{O}_{2}}$ is the oxygen solubility depending on the temperature and the liquid composition (Pye et al., 2005). Far away from the liquid/bubble interface, the glassforming liquid is considered in chemical equilibrium with an oxygen concentration $C_{\mathrm{O}_{2}, \infty}$. 
The total concentration of the species $\mathrm{M}$ is considered constant such as $C_{\mathrm{M}}=C_{\mathrm{M}^{(\mathrm{n}+\mathrm{k})+}+}$ $C_{\mathrm{M}^{\mathrm{n}}+}$ is conserved.

Due to the concentration gradients, it is expected that both oxygen and multivalent species diffuse through the liquid. If we consider that the oxidation-reduction reaction is not at equilibrium, the problem must take into account both diffusion and chemical reaction phenomena. Oxygen and the multivalent species are assumed to be diluted in the glass-forming liquid. Consequently, only the diffusion coefficients of oxygen $\mathcal{D}_{\mathrm{O}_{2}}$ and $\mathcal{D}_{\mathrm{M}^{\mathrm{n}}}$ for the reduced species in the liquid are required. Moreover, for convenient reasons, the framework is attached and centred on the bubble centre meaning that the problem can be considered in quasi steady-state regime. Due to symmetry, cylindrical polar coordinates $(r, \varphi, z)$ are used for which the $\varphi$-component of the velocity and all derivatives with respect to this coordinate are equal to zero. So, the advection-diffusionreaction equations are the following

$$
\begin{aligned}
u_{r} \frac{\partial C_{\mathrm{O}_{2}}}{\partial r}+u_{z} \frac{\partial C_{\mathrm{O}_{2}}}{\partial z} & =\mathcal{D}_{\mathrm{O}_{2}}\left[\frac{1}{r} \frac{\partial}{\partial r}\left(r \frac{\partial C_{\mathrm{O}_{2}}}{\partial r}\right)+\frac{\partial^{2} C_{\mathrm{O}_{2}}}{\partial z^{2}}\right]+\frac{k \dot{\zeta}}{4} \\
u_{r} \frac{\partial C_{\mathrm{M}^{\mathrm{n}+}}}{\partial r}+u_{z} \frac{\partial C_{\mathrm{M}^{\mathrm{n}+}}}{\partial z} & =\mathcal{D}_{\mathrm{M}^{\mathrm{n}+}}\left[\frac{1}{r} \frac{\partial}{\partial r}\left(r \frac{\partial C_{\mathrm{M}^{\mathrm{n}}}}{\partial r}\right)+\frac{\partial^{2} C_{\mathrm{M}^{\mathrm{n}+}}}{\partial z^{2}}\right]+\dot{\zeta} .
\end{aligned}
$$

The velocity components $\left(u_{r}, u_{z}\right)$ are given by the Hadamard-Rybczynski's solution, see equations (18) and (19). The quantity $\dot{\zeta}$ is the chemical reaction rate which can be written as follows

$$
\dot{\zeta}=k_{+} C_{\mathrm{M}^{(\mathrm{n}+\mathrm{k})+}}-k_{-} C_{\mathrm{M}^{\mathrm{n}+}} C_{\mathrm{O}_{2}}^{k / 4},
$$

in which $k_{+}$and $k_{-}$are the forward and backward kinetic constants respectively. If the chemical equilibrium is fulfilled, the rate of reaction is equal to zero and the ratio $k_{+} / k_{-}$ is equal to the equilibrium constant $K_{\mathrm{M}^{(\mathrm{n}+\mathrm{k})+/ \mathrm{n}+}}$ given by eq. (3).

\subsection{Normalisation of the problem}

The problem is normalised such as the space coordinates are divided by the bubble diameter $2 a$. The terminal velocity $V_{\mathrm{HR}}$, eq. (1), is used to normalise the velocity field. The dimensionless oxygen concentration is written as follows

$$
C_{1}=\frac{C_{\mathrm{O}_{2}}}{C_{\mathrm{O}_{2}, 0}},
$$

and the reduced species is normalised by

$$
C_{2}=\frac{C_{\mathrm{M}^{\mathrm{n}+}}}{C_{\mathrm{M}}}
$$

The dimensionless concentration $C_{1}$ corresponds to the local oxygen saturation while $C_{2}$ is the redox state.

The dimensionless system of two advection-diffusion-reaction equations takes the following form

$$
\begin{aligned}
& u_{r} \frac{\partial C_{1}}{\partial r}+u_{z} \frac{\partial C_{1}}{\partial z}=\frac{1}{\mathrm{Pe}}\left[\frac{1}{r} \frac{\partial}{\partial r}\left(r \frac{\partial C_{1}}{\partial r}\right)+\frac{\partial^{2} C_{1}}{\partial z^{2}}\right]+\frac{k \mathrm{Da}}{4 \mathrm{Pe}} \dot{\zeta}\left(C_{1}, C_{2}\right), \\
& u_{r} \frac{\partial C_{2}}{\partial r}+u_{z} \frac{\partial C_{2}}{\partial z}=\frac{\mathcal{D}}{\operatorname{Pe}}\left[\frac{1}{r} \frac{\partial}{\partial r}\left(r \frac{\partial C_{2}}{\partial r}\right)+\frac{\partial^{2} C_{2}}{\partial z^{2}}\right]+\frac{\beta \mathrm{Da}}{\operatorname{Pe}} \dot{\zeta}\left(C_{1}, C_{2}\right),
\end{aligned}
$$


in which $\mathrm{Pe}, \mathrm{Da}, \mathcal{D}$ and $\beta$ are defined by

$$
\begin{aligned}
& \mathrm{Pe}=\frac{2 a V_{\mathrm{HR}}}{\mathcal{D}_{\mathrm{O}_{2}}}, \\
& \mathcal{D}=\frac{\mathcal{D}_{\mathrm{M}^{(\mathrm{n}+\mathrm{k})+}}}{\mathcal{D}_{\mathrm{O}_{2}}}, \\
& \mathrm{Da}=\frac{4 a^{2} k_{+} C_{\mathrm{M}}}{C_{\mathrm{O}_{2}, 0} \mathcal{D}_{\mathrm{O}_{2}}}, \\
& \beta=\frac{C_{\mathrm{O}_{2}, 0}}{C_{\mathrm{M}}} .
\end{aligned}
$$

The first dimensionless number Pe is the Péclet number ratio between the characteristic diffusion time to the advection time. The second dimensionless group is the second Damköhler number measuring the importance of the chemical kinetics with the diffusion process (Cussler, 2009). The dimensionless parameter $\mathcal{D}$ is the ratio of the diffusion coefficient of $\mathrm{M}^{(\mathrm{n}+\mathrm{k})+}$ to the diffusion coefficient of oxygen. The last parameter is a ratio of the oxygen concentration at the bubble/glass-forming liquid interface to the total concentration of M. This quantity is expected to be small as it will be verified in $\S 4$.

The two equations (10) and (11) have to be completed by boundary conditions. At the bubble surface, the Henry's law is used while the reduced species is assumed to have no flux (homogeneous Neumann condition). Far away from the bubble interface, the chemical equilibrium is fulfilled. In dimensionless form, the boundary conditions are the following:

For $\|\boldsymbol{x}\|=1 / 2$ :

$$
\begin{aligned}
C_{1} & =1, \\
\frac{\partial C_{2}}{\partial n} & =0,
\end{aligned}
$$

and when $\|\boldsymbol{x}\| \rightarrow \infty$ :

$$
\begin{aligned}
C_{1} & \rightarrow \mathrm{Sa}_{\infty}, \\
C_{2} & \rightarrow C_{2, \infty},
\end{aligned}
$$

with

$$
\mathrm{Sa}_{\infty}=\frac{1}{C_{\mathrm{O}_{2}, 0}}\left[\frac{K_{\mathrm{M}^{(\mathrm{n}+\mathrm{k})+/ \mathrm{n}+}}\left(1-C_{2, \infty}\right)}{C_{2, \infty}}\right]^{4 / k},
$$

and $C_{2, \infty}$ the redox state far away from the bubble interface.

The dimensionless rate of reaction $\dot{\zeta}$ is equal to

$$
\dot{\zeta}=1-C_{2}-\frac{\left(1-C_{2, \infty}\right) C_{2} C_{1}^{k / 4}}{C_{2, \infty} \operatorname{Sa}_{\infty}^{k / 4}} .
$$

Finally, recall that the dimensionless velocity components in the cylindrical polar coordinates $(r, \varphi, z)$ given by the Hadamard-Rybczynski's solution are (Pigeonneau, 2009)

$$
\begin{aligned}
& u_{r}=\frac{r z}{4\left(r^{2}+z^{2}\right)^{3 / 2}}, \\
& u_{z}=-1+\frac{r^{2}+2 z^{2}}{4\left(r^{2}+z^{2}\right)^{3 / 2}} .
\end{aligned}
$$


(a)

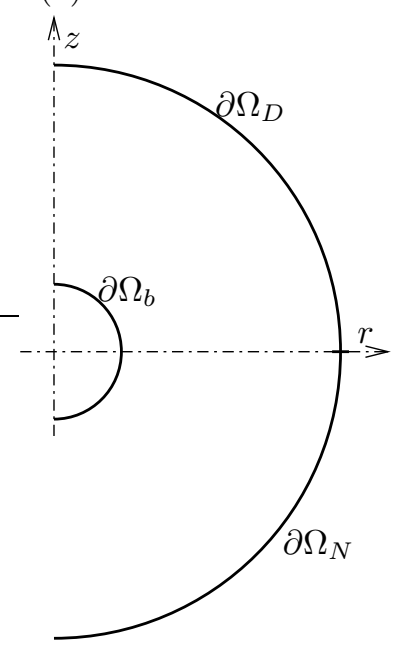

$\mathrm{Pe}<1$ (b)

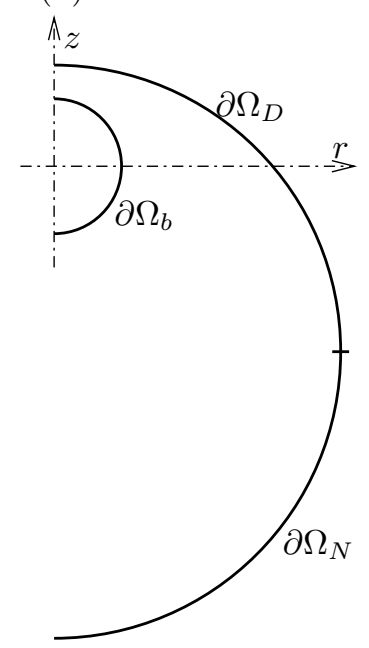

Pe $>1$

Figure 1: Axisymetric computation domain around a rising bubble with (a) the centred bubble domain used for small Péclet number and (b) the domain outside the bubble is shifted forward to take into the bubble wake.

\section{Numerical method}

The dimensionless equations (10) and (11) completed by the boundary conditions (16a)-(16d) are numerically solved using the $\mathrm{C}++$ library Rheolef developed by Saramito (2018). According to Pigeonneau et al. (2014), the finite computational domain is adapted as a function of the Péclet number as shown in Figure 1. When the bubble motion is weak, i.e. for $\mathrm{Pe}<1$, the mass transfer is driven by the diffusion process. In this limit, the spherical symmetry is predominant. Consequently, the computational domain is centred on the bubble as shown in Figure 1(a). The radius of the external circle is taken equal to 5 , i.e. ten times of the bubble radius. Conversely, when the bubble motion is larger, i.e. for $\mathrm{Pe}>1$, a solutal wake appears at the rear of the bubble. To catch this wake, the domain is centred downward as shown in Figure 1(b). The radius of the external circle is taken equal to 20 , i.e. forty times larger than the bubble radius.

Boundaries are decomposed in three parts. The first corresponds to the bubble interface, noted $\partial \Omega_{b}$ in Figure 1. For the outer boundary, the circle is cut in two parts, $\partial \Omega_{D}$ in the upward area of the bubble and $\partial \Omega_{N}$ in downward area of the bubble. This decomposition comes from the sign change of the dot product of $\boldsymbol{u}$ and the exterior unit normal $\boldsymbol{n}$. On $\partial \Omega_{D}$ in which $\boldsymbol{u} \cdot \boldsymbol{n}<0$, Dirichlet boundary conditions corresponding to the inflow conditions are both applied on $C_{1}$ and $C_{2}$ while on $\partial \Omega_{N}$, the natural Neumann conditions are imposed on $C_{1}$ and $C_{2}$. This unique decomposition ensures the numerical 


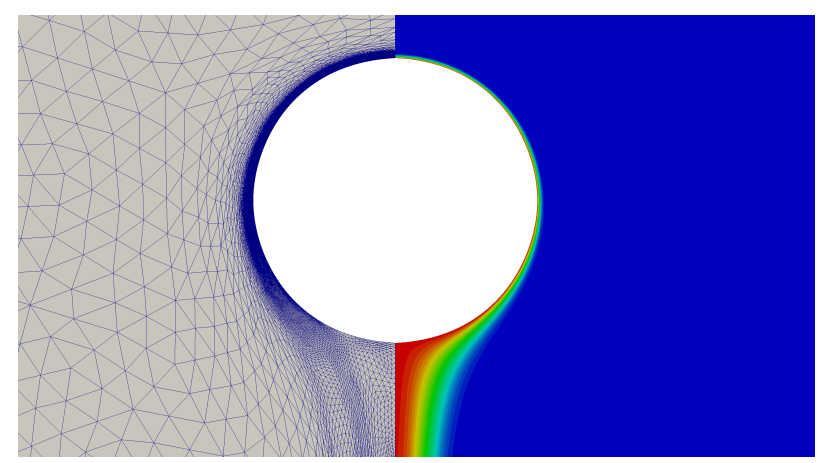

Figure 2: Mesh and $C_{1}$ concentration obtained after five remeshings around the bubble when $\mathrm{Pe}=10^{4}$ and $\mathrm{Da}=10^{2}$.

stability. In summary, the boundary conditions are the following

$$
\begin{aligned}
& \left.\begin{array}{c}
C_{1}=1, \\
\frac{\partial C_{2}}{\partial n}=0,
\end{array}\right\} \forall \boldsymbol{x} \in \partial \Omega_{b}, \\
& \left.\begin{array}{l}
C_{1}=\mathrm{Sa}_{\infty}, \\
C_{2}=C_{2, \infty},
\end{array}\right\} \forall \boldsymbol{x} \in \partial \Omega_{D}, \\
& \left.\begin{array}{l}
\frac{\partial C_{1}}{\partial n}=0, \\
\frac{\partial C_{2}}{\partial n}=0,
\end{array}\right\} \forall \boldsymbol{x} \in \partial \Omega_{N} .
\end{aligned}
$$

To ensure numerical stability, a discontinuous Galerkin finite element formulation is used to solve the two coupled equations. The upwing bilinear form as presented in (Di Pietro and Ern, 2012) is used to preserve the coercivity property. The discretisation of the domain is achieved using triangles. A quadratic discontinuous Lagrange elements $\mathbb{P}_{2 d}$ are used.

Due to the non-linearity of the chemical reaction source terms, the coupled equation is solved using a damped-Newtow method (Saramito, 2018). Moreover, to catch the boundary layer around the bubble, the mesh is adapted using the method presented by Hecht (2006). The remeshing criterion is based on the absolute value of $C_{1}$. For every set of data, five remeshings are achieved to obtain a steady-state solution.

For instance, Figure 2 depicts the mesh around the bubble on the left and $C_{1}$ concentration on the right obtained after five remeshings for a particular case with $\mathrm{Pe}=10^{4}$ and $\mathrm{Da}=10^{2}$. The other parameters of the system of equations will be more detailed in the next section. For this particular Péclet number, the boundary layer development is well captured by the numerical method. As expected for this kind of problem with mobile interface, high value of $C_{1}$ concentration is created in the wake of the bubble justifying the downward shift of the numerical domain at large Péclet number.

\section{Results and discussion}

In the following, the numerical computations solving the system of equations presented previously are applied to two kinds of glass-forming liquids. 


\begin{tabular}{ccc} 
Species & $A\left(\mathrm{~m}^{2} / \mathrm{s}\right)$ & $B(\mathrm{~K})$ \\
\hline $\mathrm{O}_{2}$ & $3 \cdot 10^{-3}$ & 26580 \\
$\mathrm{Fe}^{2+}$ & $1.07 \cdot 10^{-3}$ & 26100 \\
\hline
\end{tabular}

Table 1: Coefficients $A$ and $B$ of the diffusion coefficient written as $A e^{-B / T}$ for $\mathrm{O}_{2}$ and $\mathrm{Fe}^{2+}$ used for the numerical computations.

\subsection{Soda-lime-silica glass-forming liquid with iron}

Numerical method is first applied to soda-lime-silica glass-forming liquid with iron as multivalent species. The composition is a window glass with less than one percent of iron content. The accurate glass composition is given by Pigeonneau et al. (2010). The equilibrium constant of the iron reaction is written as follows

$$
K_{\mathrm{Fe}^{3+/ 2+}}=\exp \left(-\frac{\Delta H_{\mathrm{Fe}^{3+/ 2+}}}{\mathcal{R} T}+\frac{\Delta S_{\mathrm{Fe}^{3+/ 2+}}}{\mathcal{R}}\right),
$$

with $\Delta H_{\mathrm{Fe}^{3+/ 2+}}=140.7 \mathrm{~kJ} \mathrm{~mol}^{-1}$ and $\Delta S_{\mathrm{Fe}^{3+/ 2+}}=64.57 \mathrm{~J} \mathrm{~mol}^{-1} \mathrm{~K}^{-1}$ according to Beerkens (2004), $T$ is the absolute temperature and $\mathcal{R}$ the universal gas constant.

The diffusion coefficients, written as $A e^{-B / T}$, is taken from the reference (Beerkens, 2004 ) for the oxygen and from the data of Rüssel (1989) for iron. Table 1 provides $A$ and $B$ for these two species for window glass.

Numerical computations have been achieved for a particular temperature equal to $1400^{\circ} \mathrm{C}$ which gives a diffusion ratio $\mathcal{D}=0.47$. This means that the diffusion coefficients of oxygen and iron are the same order of magnitude. The numerical computations are first performed with an iron content equal to $0.1 \mathrm{wt} \%$ and bulk redox ratio equal to $C_{2, \infty}=0.25$. The range of Péclet number is $\left[10^{-3} ; 10^{5}\right]$ while for Damköhler number the range is set equal to $\left[10^{-2} ; 10^{6}\right]$. The other dimensionless parameters are $\beta=8.95 \cdot 10^{-3}$ and $\mathrm{Sa}_{\infty}=2.52 \cdot 10^{-2}$.

To see the effect of the chemical reaction at small Péclet number, the field of $C_{1}$ is depicted in Figure 3 for $\mathrm{Pe}=10^{-2}$ and for $\mathrm{Da}=10^{-2}$ on the left and for $\mathrm{Da}=10^{6}$ on the right. At small Damköhler number, $C_{1}$ behaves smoothly around the bubble. Close to the bubble interface, the concentration gradient stays uniform meaning that the bubble motion does not play a significant role. At large Damköhler number, shown in Figure 3b, the spherical symmetry is noticed. A large gradient of $C_{1}$ is clearly observed close to the bubble interface leading to an increase of the mass flux.

The $C_{2}$ field is also shown for $\mathrm{Pe}=10^{-2}$ and for $\mathrm{Da}=10^{-2}$ in Figure 4a. The scale of variation of $C_{2}$ is very small. The value of $C_{2}$ is quasi-equal to the boundary condition given in the exterior boundary, i.e. $\approx C_{2, \infty}$. The solution of $C_{2}$ for $\mathrm{Pe}=10^{-2}$ and for $\mathrm{Da}=10^{6}$ depicted in Figure $4 \mathrm{~b}$ changes dramatically. The range of variation of $C_{2}$ is now larger than for the case obtained at $\mathrm{Da}=10^{-2}$. The spherical symmetry around the bubble is also verified.

In Figure 5, profiles of $C_{1}$ and $C_{2}$ are plotted as a function of $r$ in the plane $z=0$ for the same case when $\mathrm{Pe}=10^{-2}$ and for $\mathrm{Da}=10^{-2}$ and $\mathrm{Da}=10^{6}$. The numerical solution of $C_{1}$ when $\mathrm{Da}=10^{-2}$ is compared to the pure diffusion solution given by

$$
C_{1}=C_{1, \infty}+\frac{1-C_{1, \infty}}{2 r},
$$


(a) $\mathrm{Da}=10^{-2}$

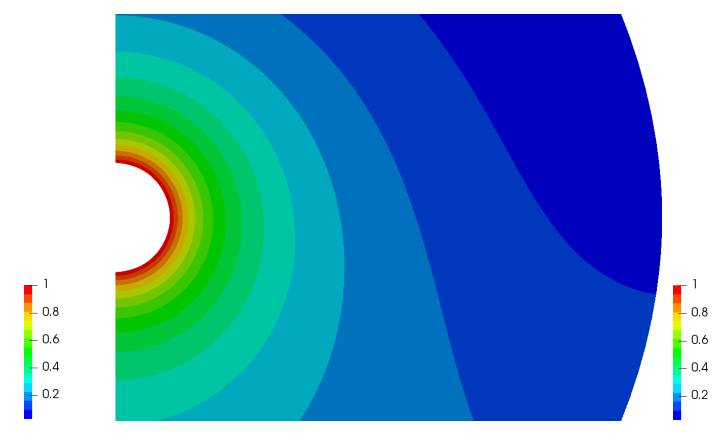

Figure 3: $C_{1}$ around the bubble at $\mathrm{Pe}=10^{-2}$ and for (a) $\mathrm{Da}=10^{-2}$ and (b) $\mathrm{Da}=10^{6}$ for a window glass at $1400^{\circ} \mathrm{C}$ with 0.1 wt $\%$ of iron and $C_{2, \infty}=0.25$.

(a) $\mathrm{Da}=10^{-2}$

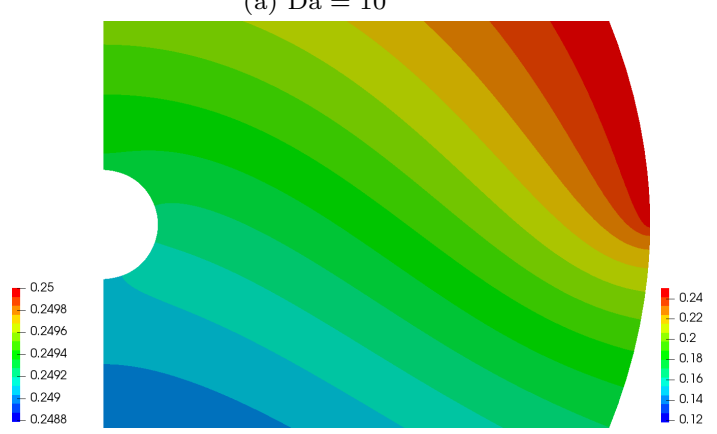

(b) $\mathrm{Da}=10^{6}$

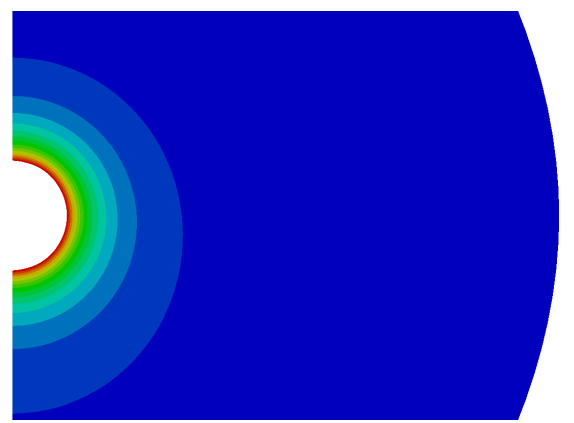

(b) $\mathrm{Da}=10^{6}$

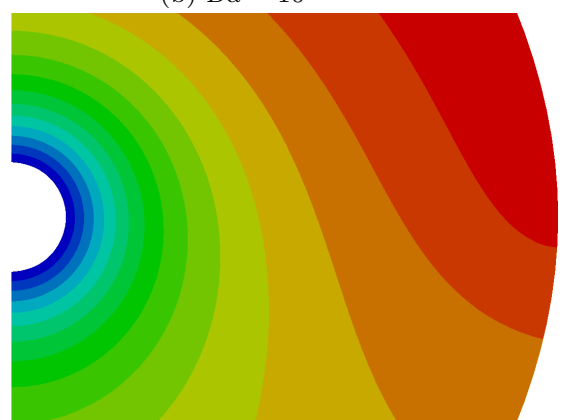

Figure 4: $C_{2}$ around the bubble at $\mathrm{Pe}=10^{-2}$ and for (a) $\mathrm{Da}=10^{-2}$ and (b) $\mathrm{Da}=10^{6}$ for a window glass at $1400^{\circ} \mathrm{C}$ with $0.1 \mathrm{wt} \%$ of iron and $C_{2, \infty}=0.25$. 
(a) $C_{1}$

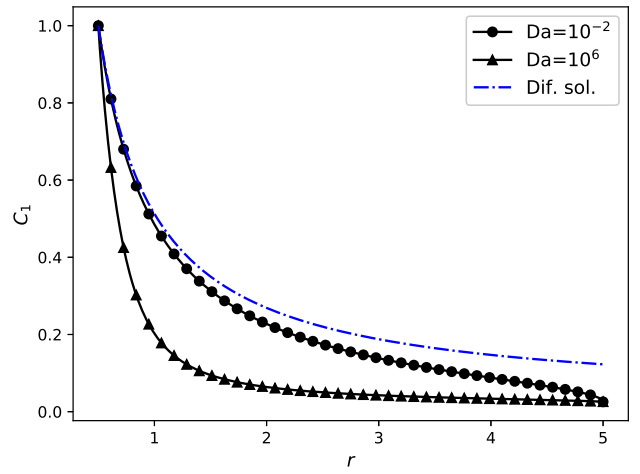

(b) $C_{2}$

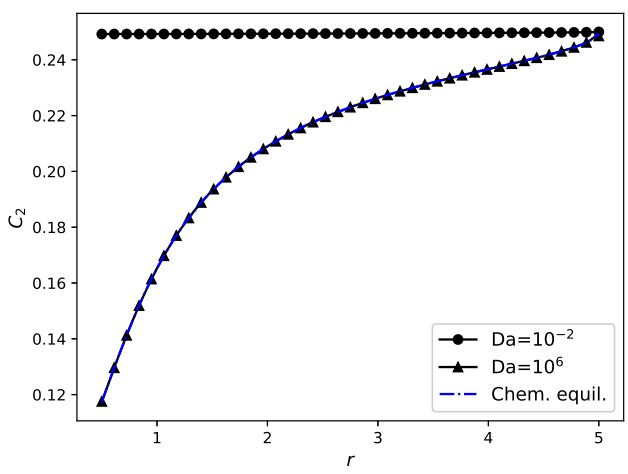

Figure 5: $C_{1}$ and $C_{2}$ as a function of $r$ for $\mathrm{Pe}=10^{-2}$ and for $\mathrm{Da}=10^{-2}$ and $\mathrm{Da}=10^{6}$ for a window glass at $1400{ }^{\circ} \mathrm{C}$ with $0.1 \mathrm{wt} \%$ of iron and $C_{2, \infty}=0.25$.

depicted in Figure 5a in blue dash-dot line. This solution is obtained for an infinite domain. Close to bubble interface, the two solutions are very similar. Due to the finite domain used in the numerical simulation, the disagreement between the two solutions increases far away from the bubble interface. This drawback is less important since the main goal of these computations is to determine the Sherwood number. Indeed, this quantity depends mainly on the solution close to this interface which is very well captured by the numerical solution.

In Figure $5 \mathrm{~b}$, for $\mathrm{Da}=10^{-2}$, we could notice that $C_{2}$ is constant in the investigated $r$ range. Once again, this constant solution is the result of pure diffusion equation completed to the boundary conditions used to solve $C_{2}$.

At large Damköhler number, the $C_{1}$ profile is stiffer than in the case at small Damköhler number as it is shown in Figure $5 \mathrm{a}$. In this situation, the effect of the computation in a finite domain is least due to the increase of the gradient around the bubble interface. For $\mathrm{Da}=10^{6}$, the chemical reaction drives the solution of $C_{2}$. To control this assertion, the numerical solution of $C_{2}$ is compared to the solution obtained by assuming the chemical equilibrium given by

$$
C_{2}=\frac{C_{2, \infty} \mathrm{Sa}_{\infty}^{k / 4}}{C_{2, \infty} \mathrm{Sa}_{\infty}^{k / 4}+\left(1-C_{2, \infty}\right) C_{1}^{k / 4}} .
$$

This equation is plotted in Figure $5 \mathrm{~b}$ in blue dash-dot line using the numerical solution of $C_{1}$. The two solutions of $C_{2}$ are totally superposed meaning that the chemical equilibrium is established over all the domain.

To see the influence of chemical reaction when the bubble motion is also relevant, i.e. $\mathrm{Pe} \gg 1$, the field of $C_{1}$ around the bubble is represented by the two extreme values of the Damköhler equal to $\mathrm{Da}=10^{-2}$ in Figure $6 \mathrm{a}$ and $\mathrm{Da}=10^{6}$ in Figure $6 \mathrm{~b}$. The Péclet number is equal to $\mathrm{Pe}=10^{4}$. The formation of the boundary layer is clearly seen with an increase of the boundary layer along the bubble interface in agreement with the Levich's theory (Levich, 1962). When the Damköhler increases, the boundary layer is thinner and thinner leading to a large mass transfer.

Due to the high importance of describing the overall mass transfer for bubbles dis- 
(a) $\mathrm{Da}=10^{-2}$

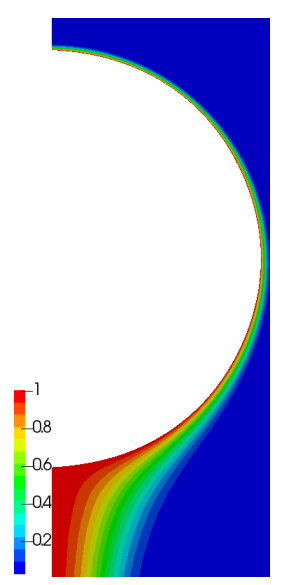

(b) $\mathrm{Da}=10^{6}$

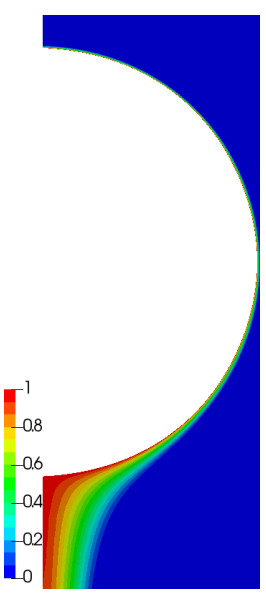

Figure 6: $C_{1}$ around the bubble at $\mathrm{Pe}=10^{4}$ and for (a) $\mathrm{Da}=10^{-2}$ and (b) $\mathrm{Da}=10^{6}$ for a window glass at $1400{ }^{\circ} \mathrm{C}$ with $0.1 \mathrm{wt} \%$ of iron and $C_{2, \infty}=0.25$.

persed in a liquid, numerical computations are mainly used to determine the Sherwood number. Recall that this dimensionless number is the ratio of the mass fluxes with and without convection (Clift et al., 1978; Bird et al., 2002). The Sherwood number can be seen as the dimensionless concentration gradient integrated over the bubble surface. In agreement with the normalisation defined in $\S 2.1$, the Sherwood number defined by

$$
\mathrm{Sh}=\frac{1}{\left(1-C_{1, \infty}\right) 2 \pi} \int_{\partial \Omega_{b}} \frac{\partial C_{1}}{\partial n} d S
$$

is assessed after each numerical computation. In eq. (26), $\partial \Omega_{b}$ is the boundary corresponding to the bubble frontier represented in Figure 1.

The Sherwood number takes also into account the chemical reaction. To see more clearly the effect of the reaction, the enhancement factor defined by (Juncu, 2002a)

$$
E_{a}=\frac{\mathrm{Sh}(\mathrm{Pe}, \mathrm{Da})}{\mathrm{Sh}(\mathrm{Pe}, \mathrm{Da}=0)}
$$

is also computed.

As seen in eqs. (10) and (11), the importance of the chemical reaction is controlled by the ratio of Da to Pe. This quantity defined by

$$
\alpha=\frac{\mathrm{Da}}{\mathrm{Pe}},
$$

has been used in (Pigeonneau et al., 2014) to study the boundary layer solution around a rising bubble. This dimensionless number corresponds to the ratio of the characteristic time scale of the reaction to the characteristic time of advection.

Figure 7 represents $E_{a}$, defined by eq. (27), plotted as a function of $\alpha$ for various Péclet numbers. For each Péclet number, the general behaviour of $E_{a}$ is to grow from 1 to an asymptotic value depending on the Péclet number. The behaviour at large value 


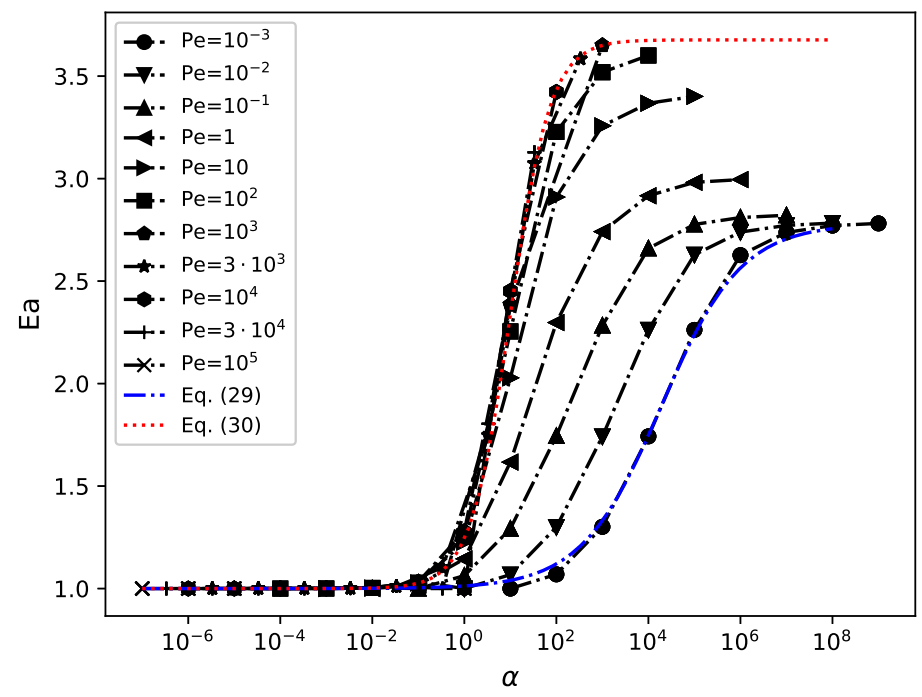

Figure 7: $E_{a}$ as a function of $\alpha$ for various Pe for a window glass at $1400{ }^{\circ} \mathrm{C}$ with $0.1 \mathrm{wt} \%$ of iron and $C_{2, \infty}=0.25$.

of $\alpha$ is similar to the Burke-Schumann limit (Burke and Schumann, 1928) corresponding to the case of infinitely fast chemistry. Conversely to the previous works provided in (Pigeonneau et al., 2014) in which exact solutions are obtained, this task is more difficult in the present case due to the non-linearity of the reversible chemical reaction investigated herein. Nevertheless, the typical solutions found in (Pigeonneau et al., 2014) are guide to establish simple approximations of the numerical solutions.

To estimate the enhancement factor for small Péclet number as a function of $\alpha$, the following correlation

$$
E_{a, 0}=\frac{1+a E_{a, 0}^{\max } \sqrt{\alpha}}{1+a \sqrt{\alpha}}
$$

is proposed, with $E_{a, 0}^{\max }$ the maximum of the enhancement factor observed at large value of $\alpha$ and $a$ a numerical coefficient to describe the transition between slow and fast chemical kinetics. This approximate solution is represented in Figure 7 in blue dash-dot line with $E_{a, 0}^{\max }=2.78$ and $a=7.25 \cdot 10^{-3}$.

When the Péclet number increases, the transition between the absence and the relevance of the chemical reaction is sharper. Consequently, the enhancement factor at large Péclet number can be approximated by the following relation

$$
E_{a, \infty}=\frac{1+b E_{a, \infty}^{\max } \alpha}{1+b \alpha},
$$

in which $E_{a, \infty}^{\max }$ is the maximum of the enhancement factor for large $\alpha$ and $b$ a numerical coefficient to proper describe the transition. Equation (30) with $E_{a, \infty}^{\max }=3.67$ and $b=0.1$ has been used to plot the red dotted line in Figure 7.

Figure 8 depicts the Sherwood number as a function of Péclet number for various Da for a window glass at $1400^{\circ} \mathrm{C}$ with $0.1 \mathrm{wt} \%$ of iron and $C_{2, \infty}=0.25$. For small 


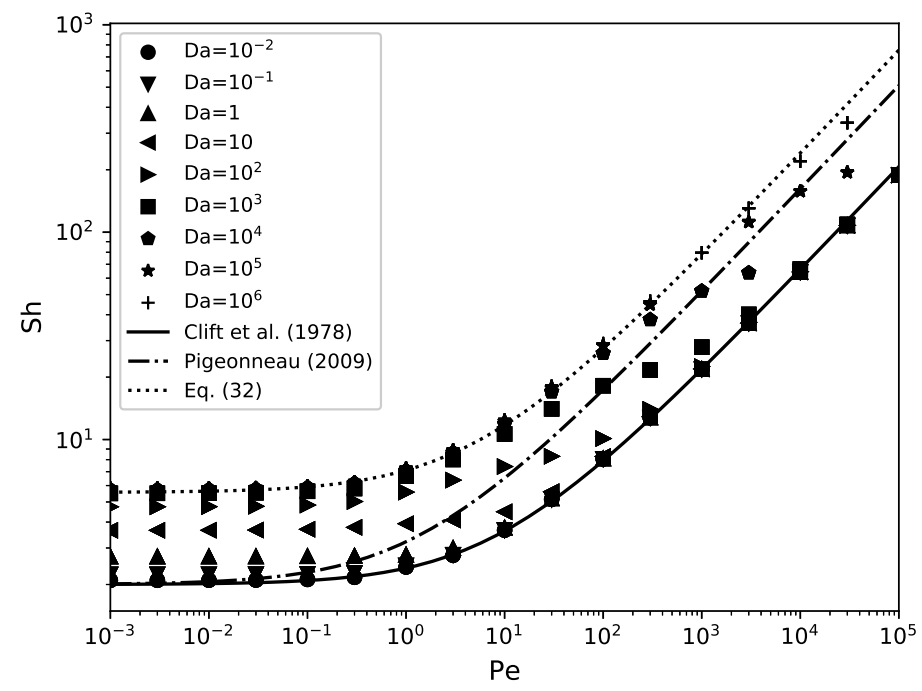

Figure 8: Sh as a function of Pe for various Da for a window glass at $1400{ }^{\circ} \mathrm{C}$ with $0.1 \mathrm{wt} \%$ of iron and $C_{2, \infty}=0.25$.

Damköhler number, Sh obeys to the correlation

$$
\mathrm{Sh}(\mathrm{Pe})=1+\left(1+0.564 \mathrm{Pe}^{2 / 3}\right)^{3 / 4}
$$

provided in Clift et al. (1978) obtained in the case of creeping flow with mobile interface and without chemical reaction. For small Péclet number, the Sherwood number is equal to 2 and when the Péclet number is much larger than 1 the Levich's solution (Levich, 1962 ) is found. This correlation is represented in solid line in Figure 8.

When the Damköhler number increases meaning that the reaction is faster, the Sherwood number increases meaning that the mass transfer is enhanced by the chemical reaction. For small Péclet number, the enhancement is practically insensitive to the Péclet number for a given Damköhler number.

When the Péclet number becomes larger than the Damköhler number, the enhancement due to the chemical reaction decreases strongly. This result can be easily explained by noting that the source terms in equations (10) and (11) are less important when $\alpha$ decreases. In the limit of a small $\alpha$, the Sherwood number converges to the solution without reaction. This fact, already underlined by Pigeonneau et al. (2014) in the simplest case of linear reversible reaction, is a consequence of the interaction of the two boundary layers. The former is due to the chemical reaction scaling as $1 / \sqrt{\mathrm{Da}}$ while the latter comes from the advection characterised by a layer proportional to $1 / \sqrt{\mathrm{Pe}}$.

In Figure 8, the solution obtained by Pigeonneau (2009) is plotted in dash-dot line. This solution underestimates the mass transfer in a large proportion at small Péclet number. Indeed, the solution provided in (Pigeonneau, 2009) has been achieved in a particular case for which the diffusion of iron is assumed equal to zero and when the redox reaction is considered instantaneous. 


\begin{tabular}{|c|cc||cc|}
\hline $\mathcal{D}$ & $E_{a, 0}^{\max }$ & $a$ & $E_{a, \infty}^{\max }$ & $b$ \\
\hline $4.7 \cdot 10^{-1}$ & 9.5 & $2.5 \cdot 10^{-3}$ & 13.1 & $3 \cdot 10^{-2}$ \\
$4.7 \cdot 10^{-2}$ & 1.89 & $2.5 \cdot 10^{-2}$ & 7.1 & $10^{-1}$ \\
$4.7 \cdot 10^{-3}$ & 1.05 & $2.5 \cdot 10^{-2}$ & 6.2 & $2 \cdot 10^{-1}$ \\
\hline
\end{tabular}

Table 2: Values of $E_{a, 0}^{\max }, a, E_{a, \infty}^{\max }$ and $b$ of equations (29) and (30) for a silico-sodo-lime glass-forming liquid at $1400^{\circ} \mathrm{C}$ with 0.2 wt $\%$ of iron and $C_{2, \infty}=0.45$ and $\mathcal{D}=4.7 \cdot 10^{-1}, 4.7 \cdot 10^{-2}$ and $4.7 \cdot 10^{-3}$.

To have a correlation of the Sherwood number of a function of the Péclet and Damköhler numbers, a correlation using the two previous relations of $E_{a}$ can be used. Indeed, when the Péclet number is small, the Sherwood number is expected to be equal to $2 E_{a, 0}(\alpha)$ while when the Péclet number is much larger than one, Sh must be approximately equal to $0.651 E_{a, \infty}(\alpha) \sqrt{\mathrm{Pe}}$. According to the correlation provided by Clift et al. (1978) and recalled above, eq. (31), a correlation of the Sherwood is proposed as follows

$$
\operatorname{Sh}(\mathrm{Pe}, \alpha)=E_{a, 0}(\alpha)+\left[E_{a, 0}(\alpha)^{4 / 3}+0.564 E_{a, \infty}(\alpha)^{4 / 3} \mathrm{Pe}^{2 / 3}\right]^{3 / 4} .
$$

This approximate solution has been used to plot the dotted line in Figure 8 in the Burke-Schumann limit. The agreement with the numerical results is satisfying. This kind of correlation is very useful for applications because it is easily programmed in any CFD software to describe the overall bubble dynamics.

To see the effect of the diffusion coefficient of iron, numerical computations are performed with an iron content equal to $0.2 \mathrm{wt} \%$ and a redox state $C_{2, \infty}=0.45$. Three values of the diffusion ratio $\mathcal{D}$ are been used. The first one is obtained by taking parameters given in Table 1 corresponding to the nominal case. The two other cases are computed by multiplying $\mathcal{D}$ by a factor $10^{-1}$ and $10^{-2}$. For this redox state and iron content, $\beta=4.476 \cdot 10^{-3}$ and $\mathrm{Sa}_{\infty}=6.943 \cdot 10^{-4}$.

The enhancement factor as a function of the ratio $\alpha$ is plotted in Figure 9 for the three values of the diffusion ratio $\mathcal{D}$. The decrease of $\mathcal{D}$ leads to a decrease of the effect of the chemical reaction. The approximate functions (29) and (30) are also used to fit the data for small and high Péclet values respectively. Values to fit the numerical data with the two equations are provided in Table 2 . In diffusive regime $(\mathrm{Pe} \ll 1)$, the enhancement factor decreases strongly with the diffusion ratio in agreement with the previous work reported in (Pigeonneau, 2009). At large Péclet number, the transport of the multivalent species balances the chemical reaction leading to the chemical enhancement of the mass transfer. The role playing by the diffusion coefficient has been already emphasised by Pigeonneau et al. (2014) in a simpler case in which approximate solutions were provided.

Figure 10 presents the Sherwood number as a function of the Péclet number for the three cases. In the nominal case depicted in Figure 10a, the mass transfer enhances strongly due to the increase of iron content and a large value of redox state. The effect of the chemical reaction reduces when the diffusion coefficient decreases, as it can be seen in Figure 10b and Figure 10c. For a Péclet number equal to $10^{-3}$ and a Damhöhler number equal to $10^{6}$, the Sherwood number is equal to 18.7 when $\mathcal{D}=4.7 \cdot 10^{-1}$ while Sh decreases to 3.9 when the diffusion ratio is divided by 10 and equal to 2.24 for $\mathcal{D}$ divided by 100 . It is noteworthy that for the smallest diffusion ratio, the numerical solution obtained in the current work is very similar to the case obtained by assuming the instantaneous reaction and the absence of the iron diffusion. 
(a) $\mathcal{D}=4.7 \cdot 10^{-1}$

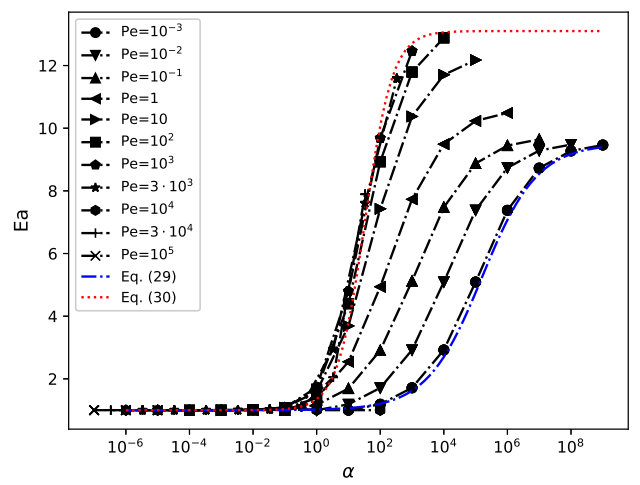

(b) $\mathcal{D}=4.7 \cdot 10^{-2}$

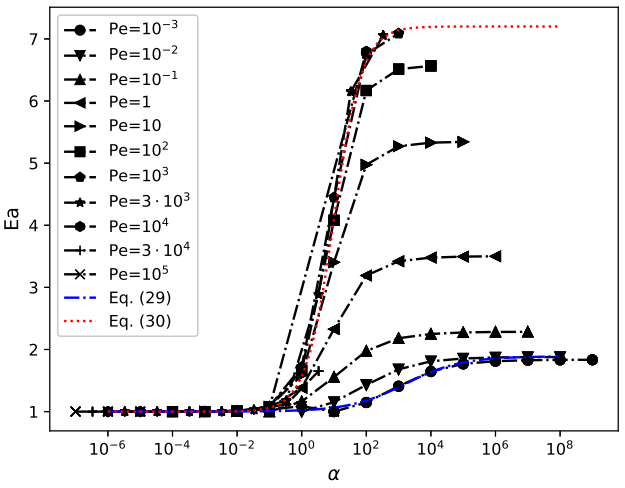

(c) $\mathcal{D}=4.7 \cdot 10^{-3}$

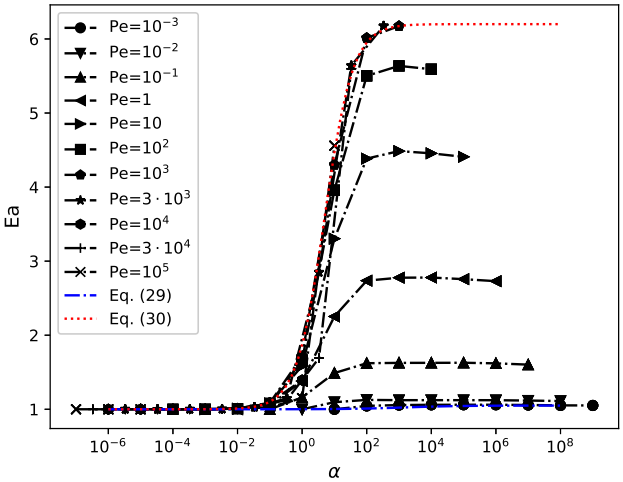

Figure 9: $E_{a}$ as a function of $\alpha$ for various Pe for a window glass at $1400^{\circ} \mathrm{C}$ with 0.2 wt $\%$ of iron and $C_{2, \infty}=0.45$. Three values of the diffusion ratio $\mathcal{D}$ are used: (a) $\mathcal{D}=4.7 \cdot 10^{-1}$ corresponding to the nominal value, (b) $\mathcal{D} \times 10^{-1}$ and (c) $\mathcal{D} \times 10^{-2}$ 
(a) $\mathcal{D}=4.7 \cdot 10^{-1}$

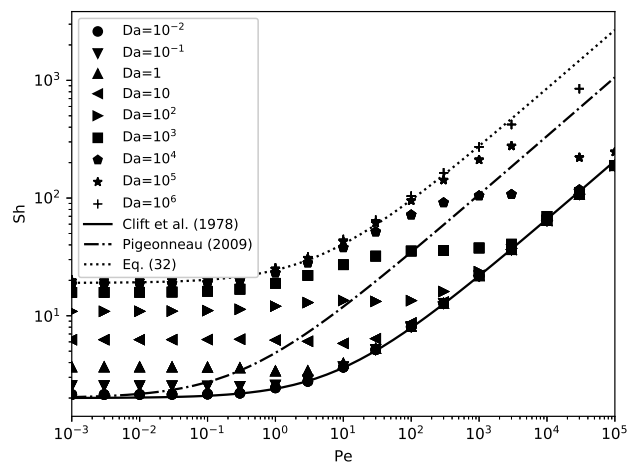

(b) $\mathcal{D}=4.7 \cdot 10^{-2}$

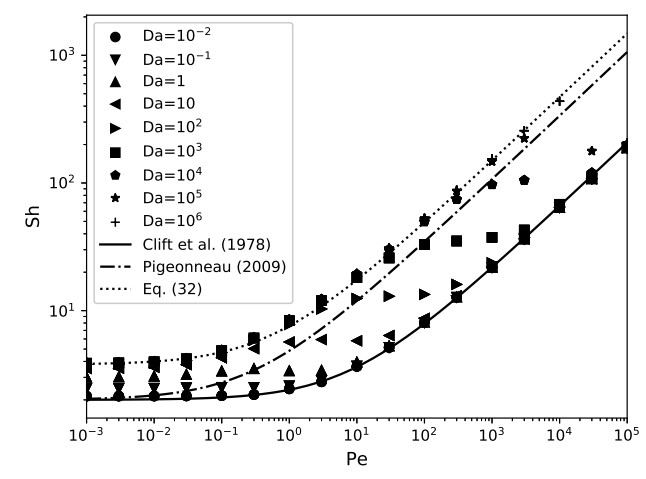

(c) $\mathcal{D}=4.7 \cdot 10^{-3}$

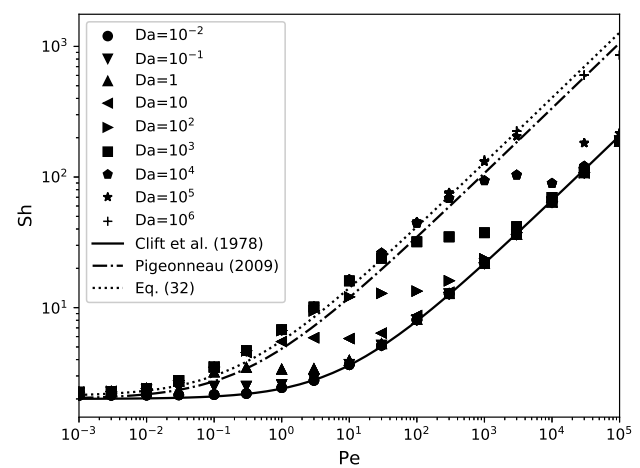

Figure 10: Sh as a function of Pe for various $\mathrm{Da}$ for a window glass at $1400{ }^{\circ} \mathrm{C}$ with 0.2 wt $\%$ of iron and $C_{2, \infty}=0.45$. Three values of the diffusion ratio $\mathcal{D}$ are used: (a) $\mathcal{D}=4.7 \cdot 10^{-1}$ corresponding to the nominal value, (b) $\mathcal{D} \times 10^{-2}$ and (c) $\mathcal{D} \times 10^{-3}$. 


\begin{tabular}{ccc} 
Species & $A\left(\mathrm{~m}^{2} / \mathrm{s}\right)$ & $B(\mathrm{~K})$ \\
\hline $\mathrm{O}_{2}$ & $3.2 \cdot 10^{-5}$ & 16140 \\
$\mathrm{Ce}^{3+}$ & $3.02 \cdot 10^{-2}$ & 29226 \\
\hline
\end{tabular}

Table 3: Coefficients $A$ and $B$ of the diffusion coefficient written as $A e^{-B / T}$ for $\mathrm{O}_{2}$ (Doremus, 1960) and $\mathrm{Ce}^{3+}$ (Claußen and Rüssel, 1997) used for numerical computations.

\begin{tabular}{cccc} 
wt $\%$ of Ce & 0.5 & 1 & 1.5 \\
\hline$C_{2, \infty}$ & 0.693 & 0.677 & 0.705 \\
$\mathrm{Sa}_{\infty}$ & 0.258 & $7.74 \cdot 10^{-2}$ & $4.563 \cdot 10^{-2}$ \\
$\beta$ & $1.818 \cdot 10^{-3}$ & $9.09 \cdot 10^{-4}$ & $6.06 \cdot 10^{-4}$ \\
$\mathcal{D}$ & & $9.6 \cdot 10^{-2}$ & \\
\hline
\end{tabular}

Table 4: Values of $C_{2, \infty}, \mathrm{Sa}_{\infty}, \beta$ and $\mathcal{D}$ for numerical computations in the case of the borosilicate with three values of cerium content at $T=1150^{\circ} \mathrm{C}$.

As for the previous iron content, equation (32) has been used to fit the Sherwood number for a large value of $\alpha$. The comparison shows that equation (32) predicts very well the Sherwood number in a large range of Péclet number.

\subsection{Borosilicate glass with cerium}

The numerical computations are now applied to a borosilicate glass-forming liquid with cerium oxide as multivalent element. In this case, the two states of oxidation are $\mathrm{Ce}^{4+}$ and $\mathrm{Ce}^{3+}$ meaning that like for iron reaction only one electron is exchanged. The enthalpy and entropy of the cerium reaction is taken from the data provided by Pinet et al. (2006). Enthalpy and entropy of this reaction are $\Delta H_{\mathrm{Ce}^{4+/ 3+}}=77.5 \mathrm{~kJ} \mathrm{~mol}^{-1}$ and $\Delta S_{\mathrm{Ce}^{4+/ 3+}}=51.07 \mathrm{~J} \mathrm{~mol}^{-1} \mathrm{~K}^{-1}$, respectively. The diffusion coefficient of oxygen is taken from the data of Doremus (1960) while the diffusion coefficient of $\mathrm{Ce}^{3+}$ has been determined using the data of Claußen and Rüssel (1997). Coefficients $A$ and $B$ to determine the diffusion coefficients of $\mathrm{O}_{2}$ and $\mathrm{Ce}^{3+}$ are provided in Table 3.

Recently, Pereira et al. (2020) studied the resorption of $\mathrm{O}_{2}$ bubble in a borosilicate molten glass with three cerium contents. Here, the same amounts of cerium are used equal to $0.5,1$ and $1.5 \mathrm{wt} \%$. The redox state has been determined and characterised in (Pereira et al., 2020). From these data, all parameters required to perform numerical simulations at $T=1150^{\circ} \mathrm{C}$ are given in Table 4 . The redox state does not change significantly for the compositions. The bulk oxygen saturation decreases with the amount of cerium content. Note also that the diffusion ratio $\mathcal{D}$ is smaller than the value for the soda-lime-silica glass-forming liquid.

In this subsection, only the enhancement factor and the Sherwood number are presented. Figure 11 presents $E_{a}$ as a function of $\alpha$ for various Péclet number and for the three amount of cerium. The overall behaviour of $E_{a}$ is similar to the previous observed in $\S 4.1$. The transition from which the chemical reaction becomes predominant occurs for both cerium contents for $\alpha$ in the range around $\left[10^{3} ; 10^{8}\right]$ when the Péclet number is less than one. Conversely, when the Péclet number is larger than one, the transition between slow chemical kinetics and the Burke-Schumann limit is in the range of $\alpha$ equal to $\left[1 ; 10^{3}\right]$. As already pinpointed above, the transition is narrower at large Pe than at small Pe. The maximum of the enhancement factor both for small and large Péclet 


\begin{tabular}{|c|cc||cc|}
\hline Ce (wt \%) & $E_{a, 0}^{\max }$ & $a$ & $E_{a, \infty}^{\max }$ & $b$ \\
\hline 0.5 & 3.32 & $3 \cdot 10^{-3}$ & 8.1 & $10^{-2}$ \\
1.0 & 5.3 & $1.25 \cdot 10^{-3}$ & 12.7 & $3 \cdot 10^{-3}$ \\
1.5 & 8.3 & $2.25 \cdot 10^{-3}$ & 19 & $2 \cdot 10^{-3}$ \\
\hline
\end{tabular}

Table 5: Values of $E_{a, 0}^{\max }, a, E_{a, \infty}^{\max }$ and $b$ of equations (29) and (30) for a borosilicate glass-forming liquid at $1150{ }^{\circ} \mathrm{C}$ with three amounts of cerium.

numbers increases with the cerium amount. The dash-dot and dotted lines corresponds to the approximate relations (29) and (30) respectively. Fitted parameters for the three cerium amounts are given in Table 5.

Figure 12 provides Sh as a function of Pe for the three values of cerium contents. The general behaviour of Sh is similar to the previous observed on the soda-lime-silica glass-forming liquid. Numerical results are compared to the correlation provided in (Pigeonneau, 2009). Due to the finite value of $\mathcal{D}$, the correlation of Pigeonneau (2009) underestimates the Sherwood number by half at large Péclet number. In the diffusion regime, i.e. $\mathrm{Pe} \ll 1$, the effect of the chemical reaction disappears completely from the correlation of Pigeonneau (2009). To determine the Sherwood number in the limit of Burke-Schumann, the correlation given by (32) has been used. The Sherwood number obtained by eq. (32) is in good agreement with the numerical solutions. This correlation uses the data provided in Table 5 .

In (Pereira et al., 2020), the $\mathrm{O}_{2}$ bubble resorption has been investigated using a high temperature furnace observation. When the cerium content increases, the shrinkage rate increases. Comparisons between experimental and numerical results are acceptable when a mass transfer model takes the Sherwood number provided by Pigeonneau (2009). If the Sherwood number found in the current work was used, the shrinkage rate should be enhanced. This ambiguity has to be investigated in the near future.

\section{Summary and conclusion}

Mass transfer around a rising bubble in a glass-forming liquid is investigated when the kinetics of an oxidation-reduction reaction is taken into account. The coupled of two advection-diffusion-reaction equations are written in dimensionless form. The two variables are the oxygen saturation and the redox state. Mainly, two dimensionless numbers corresponding to the Péclet, Pe, and Damköhler, Da, numbers are used to investigate the mass transfer. The other parameters are function of the glass-forming liquid composition and the involved multivalent species. The two coupled equations are numerically solved using a discontinuous Galerkin finite element method.

The numerical method is first applied to a soda-lime-silica glass-forming liquid. Iron species is introduced as multivalent element with two degrees of oxidation, viz. $\mathrm{Fe}^{3+}$ in oxidation state and $\mathrm{Fe}^{2+}$ in reduction state. The mass transfer is mainly quantified by the computation of the Sherwood number, Sh. The enhancement factor $E_{a}$, ratio of the Sherwood number with the chemical reaction to the Sherwood number without reaction is also investigated as a function of $\alpha=\mathrm{Da} / \mathrm{Pe}$. At small $\alpha$, the enhancement factor is close to one meaning that the chemical reaction is not significant. At large $\alpha$ corresponding to the fast chemistry, $E_{a}$ reaches an asymptotic limit larger that one. 
(a) $0.5 \mathrm{wt} \%$ of $\mathrm{Ce}$

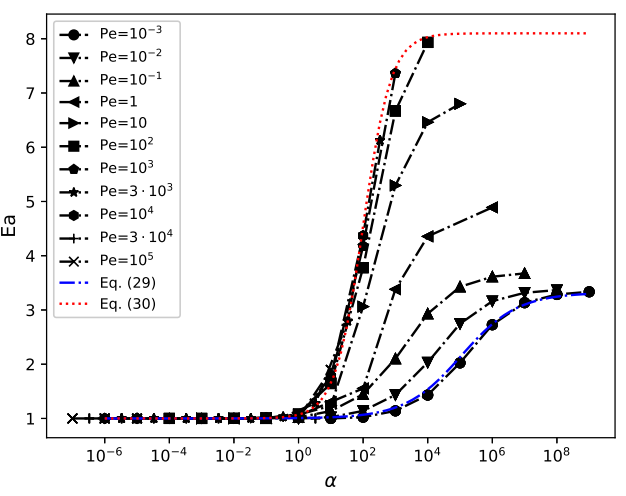

(b) $1 \mathrm{wt} \%$ of $\mathrm{Ce}$

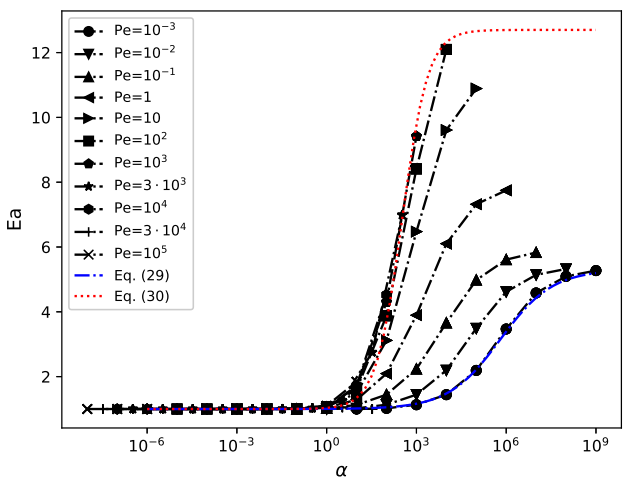

c) $1.5 \mathrm{wt} \%$ of $\mathrm{Ce}$

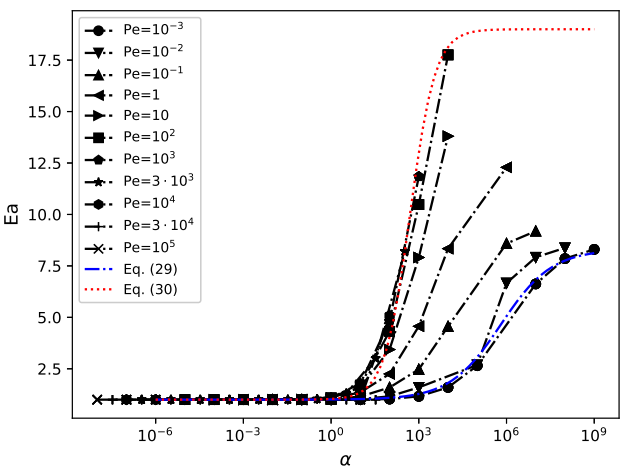

Figure 11: $E_{a}$ as a function of $\alpha$ for various Pe for a borosilicate glass at $1150{ }^{\circ} \mathrm{C}$ with (a) 0.5 wt $\%$ of $\mathrm{Ce}$, (b) $1 \mathrm{wt} \%$ of Ce and (c) $1.5 \mathrm{wt} \%$ of Ce. 
(a) $0.5 \mathrm{wt} \%$ of $\mathrm{Ce}$

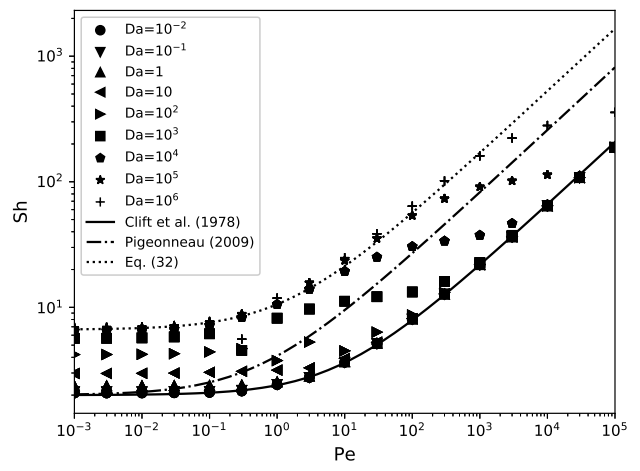

(b) $1 \mathrm{wt} \%$ of $\mathrm{Ce}$

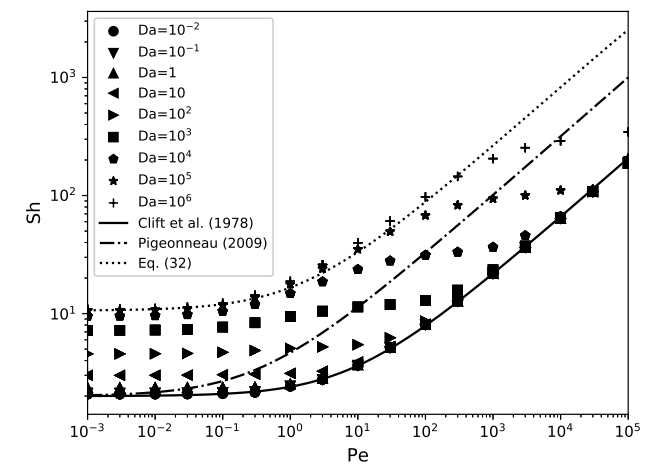

c) $1.5 \mathrm{wt} \%$ of $\mathrm{Ce}$

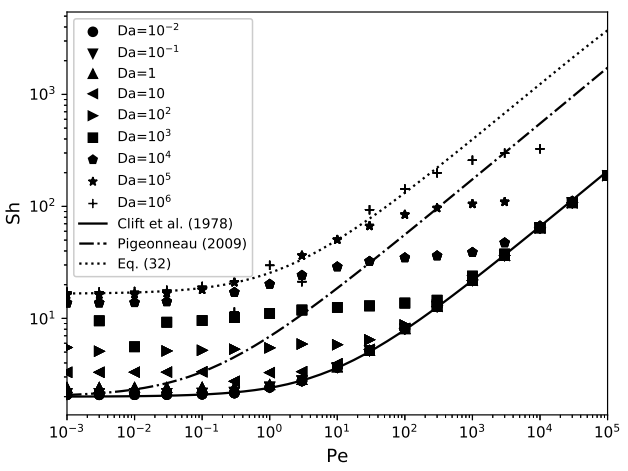

Figure 12: Sh as a function of Pe for various Da for a borosilicate glass at $1150{ }^{\circ} \mathrm{C}$ with (a) 0.5 wt $\%$ of Ce, (b) 1 wt\% of Ce and (c) 1.5 wt\% of Ce. 
This bound depends on the redox state, the amount of the multivalent species and the diffusion coefficient ratio of the multivalent species to oxygen. The transition between slow and fast chemistry depends on the Péclet number. Two simple correlations at small and large Péclet numbers are established. The Sherwood number is also compared to a new correlation proposed in this work extending the correlation in the creeping flow without reaction. This correlation can be very useful in any CFD software to describe the overall bubble dynamics.

The numerical method is also applied to a borosilicate glass-forming liquid with cerium oxide as multivalent element with $\mathrm{Ce}^{4+}$ and $\mathrm{Ce}^{3+}$ as oxidised and reduced states, respectively. The general behaviour of the mass transfer does not change for this second application. For both glass-forming liquids, the comparison with the Sherwood number established with vanishing diffusion coefficient of the multivalent element and instantaneous reaction reveals a disagreement when the diffusion of the multivalent element is not equal to zero. Moreover, the Sherwood number established in this work enhances at small Péclet number while the theory established at vanishing diffusion coefficient of the multivalent element predicts none enhancement.

These results lead to verify the relevance of the mobility of the multivalent element. Indeed, previous verification done in (Pigeonneau et al., 2010; Pereira et al., 2020) show that experiments are very well reproduced in the limit of vanishing diffusion coefficient of the multivalent element. To establish the relevance of the diffusion of the multivalent element, experiments in which advection is absent are required because, in this limit, the influence of the diffusion coefficient of the multivalent element is particularly significant.

\section{Acknowledgements}

The authors are indebted to D. Bothe from Technical University of Darmstadt (Germany), for the fruitful discussions during the preparation of this article and for his careful reading of the current article.

\section{References}

Bach, H., Baucke, F.G.K., Krause, D. (Eds.), 2001. Electrochemistry of Glasses and Glass Melts, Including Glass Electrodes. Schott Series on Glass and Glass Ceramics, Springer, Berlin.

Beerkens, R.G.C., 2004. Analysis of advanced and fast fining processes for glass melts, in: Advances in Fusion and Processing of Glass III. American Ceramic Society, New York, pp. 3-24.

Beerkens, R.G.C., de Waal, H., 1990. Mechanism of oxygen diffusion in glassmelts containing variablevalence ions. J. Am. Ceram. Soc. 73, 1857-1861.

Bird, R.B., Stewart, W.E., Lightfoot, E.N., 2002. Transport phenomena. Second ed., John Wiley and sons, New York.

Bothe, D., Kröger, M., Warnecke, H.J., 2011. A VOF-Based Conservative Method for the Simulation of Reactive Mass Transfer from Rising Bubbles. Fluid Dyn. Mater. Process. 7, 303-316.

Burke, S.P., Schumann, T.E.W., 1928. Diffusion flames. Ind. Eng. Chem. 20, 998-1004.

Cicconi, M.R., Neuville, D.R., Tannou, I., Baudelet, F., Floury, P., Paris, E., Giuli, G., 2015. Competition between two redox states in silicate melts: An in-situ experiment at the Fe K-edge and Eu L3-edge. Am. Mineral. 100, 1013-1016.

Claußen, O., Rüssel, C., 1997. Self diffusion of polyvalent ions in a borosilicate glass melt. J. Non-Cryst. Solids 215, 68-74.

Clift, R., Grace, J.R., Weber, M.E., 1978. Bubbles, Drops, and Particles. Academic Press, New York.

Cochain, B., Neuville, D.R., de Ligny, D., Roux, J., Baudelet, F., Strukelj, E., Richet, P., 2009. Kinetics of iron redox reaction in silicate melts: A high temperature Xanes study on an alkali basalt. J. Phys. Conf. Ser. 190, 012182. 
Crank, J., 1948. A diffusion problem in which the amount of diffusing substance is finite. -ii. diffusion with non-linear adsorption. Philos. Mag., Series 7 39, 140-149.

Cussler, E.L., 2009. Diffusion. Mass transfer in fluid systems. Third ed., Cambridge University Press, Cambridge.

Danckwerts, P.V., 1955. Gas absorption accompanied by chemical reaction. AIChE J. 1, 456-463.

Dani, A., Cockx, A., Guiraud, P., 2006. Direct numerical simulation of mass transfer spherical bubbles: the effect of interface contamination at low Reynolds numbers. Int. J. Chem. Reactor Eng. 4, 1-21.

Di Pietro, D.A., Ern, A., 2012. Mathematical aspects of discontinuous Galerkin methods. SpringerVerlag, Heidelberg.

Doremus, R.H., 1960. Diffusion of oxygen from contracting bubbles in molten glass. J. Amer. Ceram. Soc. $43,655-661$.

Duffy, J., Ingram, M., 1976. An interpretation of glass chemistry in terms of the optical basicity concept J. Non-Cryst. Solids 21, $373-410$

Falcone, M., Bothe, D., Marschall, H., 2018. 3D direct numerical simulations of reactive mass transfer from deformable single bubbles: An analysis of mass transfer coefficients and reaction selectivities. Chem. Eng. Sci. 177, 523-536.

Figueroa-Espinoza, B., Legendre, D., 2010. Mass or heat transfer from spheroidal gas bubbles rising through a stationary liquid. Chem. Eng. Sci. 65, 6296-6309.

Hadamard, J., 1911. Mouvement permanent lent d'une sphère liquide et visqueuse dans un liquide visqueux. C. R. Acad. Sci. Paris 152, 1735-1738.

Hecht, F., 2006. BAMG: bidimensional anisotropic mesh generator. User Guide. INRIA. Paris.

Hornyak, E.J., Weinberg, M.C., 1984. Velocity of a freely rising gas bubble in a soda-lime silicate glass melt. J. Am. Ceram. Soc. 67, C244-C246.

Jia, H., Xiao, X., Kang, Y., 2019. Investigation of a free rising bubble with mass transfer by an arbitrary Lagrangian-Eulerian method. Int. J. Heat Mass Transfer 137, 545-557.

Jucha, R.B., Powers, D., McNeill, T., Subramanian, R.S., Cole, R., 1982. Bubble rise in glassmelts. J. Am. Ceram. Soc. 65, 289-292.

Juncu, G., 2001. Unsteady heat and/or mass transfer from a fluid sphere in creeping flow. Int. J. Heat Mass Transfer 44, 2239-2246.

Juncu, G., 2002a. Conjugate mass transfer to a spherical drop accompanied by a second-order chemical reaction inside the drop. Int. J. Heat Mass Transfer 45, 3817-3829.

Juncu, G., 2002b. The influence of the Henry number on the conjugate mass transfer from a sphere: II - mass transfer accompanied by a first-order chemical reaction. Heat and Mass Transfer 38, 523-534.

Kleinman, L.S., Reed, X.B.J., 1995. Interphase mass transfer from bubbles, drops, and solid spheres Diffusional transport enhanced by external chemical reaction. Ind. Eng. Chem. Res. 34, 3621-3631.

Kleinman, L.S., Reed, X.B.J., 1996. Unsteady conjugate mass transfer between a single droplet and an ambient flow with external chemical reaction. Ind. Eng. Chem. Res. 35, 2875-2888.

Koynov, A., Khinast, J.G., Tryggvason, G., 2005. Mass transfer and chemical reactions in bubble swarms with dynamic interfaces. AIChE J. 51, 2786-2800.

Le Losq, C., Moretti, R., Oppenheimer, C., Baudelet, F., Neuville, D.R., 2020. In situ XANES study of the influence of varying temperature and oxygen fugacity on iron oxidation state and coordination in a phonolitic melt. Contrib. Mineral. Petrol. 175, 1-13.

Levich, V.G., 1962. Physicochemical hydrodynamics. Prentice Hall, Englewood Cliffs, N.J.

Li, K.W.K., Schneider, A., 1993. Rise velocities of large bubbles in viscous Newtonian liquids. J. Amer. Ceram. Soc. 76, 241-244.

Liao, Y., McLaughlin, J.B., 2000a. Bubble motion in aqueous surfactant solutions. J. Colloid Interface Sci. 224, 297-310.

Liao, Y., McLaughlin, J.B., 2000b. Dissolution of a freely rising bubble in aqueous surfactant solutions. Chem. Eng. Sci. 55, 5831-5850.

Liger-Belair, G., 2005. The Physics and Chemistry behind the Bubbling Properties of Champagne and Sparkling Wines: A State-of-the-Art Review. J. Agric. Food. Chem. 53, 2788-2802.

Marchisio, D.L., Fox, R.O., 2013. Computational models for polydisperse particulate and multiphase systems. Cambridge University Press.

Mason, R.M., Starostin, A.B., Melnik, O.E., Sparks, R.S.J., 2006. From vulcanian explosions to sustained explosive eruptions: the role of diffusive mass transfer in conduit flow dynamics. J. Volcanol. Geotherm. Res. 153, 148-165.

Mclaughlin, J.B., 1996. Numerical simulation of bubble motion in water. J. Colloid Interface Sci. 184 614-625.

Olander, D.R., 1960. Simultaneous mass transfer and equilibrium chemical reaction. AIChE J. 6, 
233-239.

Panda, A., Patel, H.V., Peters, E.A.J.F., Baltussen, M.W., Kuipers, J.A.M., 2020. A multiple resolution approach using adaptive grids for fully resolved boundary layers on deformable gas-liquid interfaces at high Schmidt numbers. Chem. Eng. Sci. 227, 115900.

Pereira, L., Vernerová, M., Kloužek, J., Laplace, A., Pigeonneau, F., 2020. Experimental and numerical studies of an oxygen single-bubble shrinkage in a borosilicate melt doped with cerium oxide. J. Am. Ceram. Soc. in press, .

Pigeonneau, F., 2009. Mass transfer of a rising bubble in molten glass with instantaneous oxidationreduction reaction. Chem. Eng. Sci. 64, 3120-3129.

Pigeonneau, F., Martin, D., Mario, O., 2010. Shrinkage of oxygen bubble rising in a molten glass. Chem. Eng. Sci. 65, 3158-3168.

Pigeonneau, F., Perrodin, M., Climent, E., 2014. Mass transfer enhancement by a reversible chemical reaction across the interface of a bubble rising under Stokes flow. AIChE J. 60, 3376-3388.

Pinet, O., Phalippou, J., Di Nardo, C., 2006. Modeling the redox equilibrium of the $\mathrm{Ce}^{4+} / \mathrm{Ce}^{3+}$ couple in silicate glass by voltammetry. J. Non-Cryst. Solids 352, 5382-5390.

Ponoth, S.S., McLaughlin, J.B., 2000. Numerical simulation of mass transfer for bubbles in water. Chem. Eng. Sci. 55, 1237-1255.

Pye, L.D., Montenero, A., Joseph, I. (Eds.), 2005. Properties of glass-forming melts. Taylor \& Francis Group, LLC.

Ruckenstein, E., Dang, V.D., Gill, W.N., 1971. Mass transfer with chemical reaction from spherical one or two components bubbles or drops. Chem. Eng. Sci. 26, 647-668.

Rybczynski, W., 1911. Uber die fortschreitende bewegun einer flussingen kugel in einem zaben medium. Bull. de l'Acad. des Sci. de Cracovie, série A 1, 40-46.

Ryskin, G., Leal, L.G., 1984. Numerical solution of free-boundary problems in fluid mechanics. Part 1. The finite-difference technique. J. Fluid Mech. 148, 1-17.

Rüssel, C., 1989. Redox reactions during cooling of glass melts - A theoretical consideration. Glass Sci Technol. 62, 199-203.

Sadhal, S.S., Ayyaswamy, P.S., Chung, J.N., 1997. Transport phenomena with drops and bubbles. Springer-Verlag, New York.

Saramito, P., 2018. Efficient C++ finite element computing with Rheolef. Version 7.0 ed., CNRS-CCSD ed.

Schreiber, H.D., 1986. Redox processes in glass-forming melts. J. Non-Cryst. Solids 84, 129-141.

Schreiber, H.D., 1987. An electrochemical series of redox couples in silicate melts: A review and applications to geochemistry. J. Geophys. Res. 92, 9225.

Schreiber, H.D., Kozak, S.J., Fritchman, A.L., Goldman, D.S., Schaeffer, H.A., 1986a. Redox kinetics and oxygen diffusion in a borosilicate melt. Phys. Chem. Glasses 27, 152-177.

Schreiber, H.D., Kozak, S.J., Merkel, R.C., Balazs, G.B., Jones, P.W.J., 1986b. Redox equilibria and kinetics of iron in a borosilicate glass-forming melt. J. Non-Cryst. Solids 84, 186-195.

Shelby, J.E., 2005. Introduction to glass science and technology. 2nd ed., The Royal Society of Chemistry, Cambridge.

Sherwood, T.K., Pigford, R.L., 1952. Absorption and extraction. McGraw-Hill Book Company, Inc. New York.

Soung, W.Y., Sears, J.T., 1975. Effects of reaction order and convection around gas-bubbles in a gasliquid reacting system. Chem. Eng. Sci. 30, 1353-1356.

Subramanian, R.S., Chi, B., 1980. Bubble dissolution with chemical reaction. Chem. Eng. Sci. 35, 2185-2194.

Weber, P.S., Marschall, H., Bothe, D., 2017. Highly accurate two-phase species transfer based on ALE interface tracking. Int. J. Heat Mass Transfer 104, 759-773.

Weiner, A., Timmermann, J., Pesci, C., Grewe, J., Hoffmann, M., Schlüter, M., Bothe, D., 2019. Experimental and numerical investigation of reactive species transport around a small rising bubble. Chem. Eng. Sci.: X 1, 100007.

Wylock, C.E., Cartage, T., Colinet, P., Haut, B., 2008. Coupling between mass transfer and chemical reactions during the absorption of $\mathrm{CO}_{2}$ in a $\mathrm{NaHCO}_{3}-\mathrm{Na}_{2} \mathrm{CO}_{3}$ brine : Experimental and theoretical study. Int. J. Chem. Reactor Eng. 6, 1-22.

Wylock, C.E., Larcy, A., Colinet, P., Cartage, T., Haut, B., 2011. Direct numerical simulation of bubble-liquid mass transfer coupled with chemical reactions: Influence of bubble shape and interface contamination. Colloids Surf., A 381, 130-138.

Yoshikawa, H., Miura, H., Kawase, Y., 1998. Dissolution of bubbles in glassmelts with equilibrium redox reactions: approximations for a moving bubble boundary. J. Mat. Sci. 33, 2701-2707. 